\title{
$\alpha$-Spinasterol, a TRPV1 receptor antagonist, elevates the seizure threshold in three acute seizure tests in mice
}

\author{
Katarzyna Socała $^{1} \cdot$ Dorota Nieoczym $^{1} \cdot$ Mateusz Pieróg $^{1} \cdot$ Piotr Wlaź $^{1}$
}

Received: 4 December 2014/ Accepted: 5 March 2015/Published online: 13 March 2015

(C) The Author(s) 2015. This article is published with open access at Springerlink.com

\begin{abstract}
Spinasterol is a plant-derived compound which was reported to act as a selective antagonist for the transient receptor potential vanilloid 1 (TRPV1) receptor. Several studies revealed that the TRPV1 receptors might modulate seizure activity in animal models of seizures and epilepsy. The aim of the present study was to investigate the effect of $\alpha$-spinasterol on the seizure threshold in three acute models of seizures, i.e., in the intravenous (i.v.) pentylenetetrazole (PTZ) seizure test, in the maximal electroshock seizure threshold (MEST) test and in the model of psychomotor seizures induced by $6 \mathrm{~Hz}$ stimulation in mice. Our results revealed significant anticonvulsant effect of $\alpha$-spinasterol in all the used seizure tests. In the i.v. PTZ test, statistically significant elevation was noted in case of the threshold for myoclonic twitches (doses of $0.1-1 \mathrm{mg} / \mathrm{kg}$ ) and generalized clonus seizures (doses of 0.5 and $1 \mathrm{mg} / \mathrm{kg}$ ) but not for tonic seizures. The studied TRPV1 antagonist also increased the threshold for tonic hindlimb extension in the MEST (doses of 0.5 and $1 \mathrm{mg}$ / $\mathrm{kg}$ ) and $6 \mathrm{~Hz}$ psychomotor seizure (doses of 0.1 and $0.5 \mathrm{mg} / \mathrm{kg}$ ) tests in mice. Furthermore, $\alpha$-spinasterol did not produce any significant impairment of motor coordination (assessed in the chimney test) and muscular strength (investigated in the grip-strength test) and it did not provoke significant changes in body temperature in mice. Based on the results of our study and the fact that $\alpha$-spinasterol is characterized by good blood-brain
\end{abstract}

Katarzyna Socała

ksocala@op.pl

1 Department of Animal Physiology, Institute of Biology and Biochemistry, Faculty of Biology and Biotechnology, Maria Curie-Skłodowska University, Akademicka 19, PL 20-033 Lublin, Poland permeability, we postulate further investigation of this compound to precisely evaluate mechanism of its anticonvulsant action and opportunity of its usage in clinical practice.

Keywords $\alpha$-spinasterol - TRPV1 receptors .

Anticonvulsant activity - Seizure threshold - Mice

\begin{tabular}{|c|c|}
\hline \multicolumn{2}{|c|}{ Abbreviations } \\
\hline $\mathrm{CB}_{1}$ & Receptor, cannabinoid type 1 receptor \\
\hline CL & Confidence limit \\
\hline $\mathrm{CS}_{50}$ & $\begin{array}{l}\text { Current strength required to induce seizure } \\
\text { response in } 50 \% \text { of mice }\end{array}$ \\
\hline DMSO & Dimethyl sulfoxide \\
\hline i.p. & Intraperitoneally \\
\hline i.v. & Intravenous \\
\hline MEST & Maximal electroshock seizure threshold \\
\hline NO & Nitric oxide \\
\hline PTZ & Pentylenetetrazole \\
\hline SEM & Standard error of the mean \\
\hline TRPV1 & Transient receptor potential vanilloid 1 receptor \\
\hline
\end{tabular}

\section{Introduction}

The transient receptor potential vanilloid 1 receptor (TRPV1), first identified in 1997 as a capsaicin receptor (Caterina et al. 1997), is a non-selective cation channel composed of six transmembrane domains with a short cation-permeable pore region (Pingle et al. 2007; Vriens et al. 2009). TRPV1 is a polymodal receptor, capable of responding to a wide range of stimuli such as noxious heat $\left(>43{ }^{\circ} \mathrm{C}\right)$, voltage, protons/cations, various natural 
compounds (capsaicin, resiniferatoxin, piperine) and endovanilloids which act as endogenous agonists (anandamide, arachidonic acid metabolites and polyamines). The TRPV1 receptors are predominantly expressed in peripheral sensory neurons, particularly in nociceptive $\mathrm{A} \delta$ and $\mathrm{C}$ fibres, where they play a crucial role in temperature sensing and noxious stimuli detection (Szallasi et al. 2007; Vriens et al. 2009). Numerous studies showed their importance in mediating various pain conditions, especially inflammatory thermal hyperalgesia and chronic pain. Therefore, TRPV1 receptors have been the most extensively studied as a molecular target for pain relief (Szallasi et al. 2007).

The distribution of the TRPV1 receptors is not limited only to the peripheral nervous systems. Their presence was also reported in the brain structures including hypothalamus, cerebellum, cerebral cortex, midbrain, hippocampus and amygdala (Premkumar and Sikand 2008; Martins et al. 2014). The TRPV1 receptors in peripheral neurons are targeted mainly by noxious or thermal stimuli. In contrast, the TRPV1 receptors in the brain are likely activated by endogenous agonists (Martins et al. 2014). It seems that the TRPV1 receptors play multiple functions within the brain including neurotransmission and synaptic plasticity (Kauer and Gibson 2009). Several studies showed that the TRPV1 receptors may be implicated in the neurobiology of addictive behavior, anxiety, mood disorders, cognition and emotion (Manna and Umathe 2012a; Martins et al. 2014).

A growing number of recent studies indicate the involvement of the TRPV1 receptors in the etiopathogenesis of epilepsy. Overexpression of the TRPV1 receptors was reported in the dentate gyrus of mice after pilocarpineinduced status epilepticus (Bhaskaran and Smith 2010) as well as in the temporal cortex and hippocampus from patients with mesial temporal lobe epilepsy (Sun et al. 2013). Furthermore, Gonzalez-Reyes et al. (2013) reported that the blockage of the TRPV1 receptors with capsazepine suppresses the seizure activity induced by 4-aminopyridine in mice and epileptiform activity in vitro. In a more recent study, $N$-oleoyldopamine (a TRPV1 receptor agonist) accelerated the pentylenetetrazole (PTZ) kindling in rats, while AMG-9810 (a TRPV1 receptor antagonist) delayed the development of seizure following repeated administration of PTZ. Likewise, in amygdala kindling in rats, $N$ oleoyldopamine and AMG-9810 exerted anti- and proconvulsant effects, respectively (Shirazi et al. 2014). Thus, it was suggested that the inactivation of the TRPV1 receptors may offer a new therapeutic approach in the treatment of epilepsy (Fu et al. 2009; Gonzalez-Reyes et al. 2013).

Brain penetration of the TRPV1 receptor antagonists is a critical feature that is highly desirable for studying their effects on seizure activity. Poor blood-brain barrier permeability is an obstacle for systemic administration of some commercially available TRPV1 antagonists. The second drawback of many TRPV1 antagonists is an induction of severe hyperthermia (Premkumar and Sikand 2008; Trevisan et al. 2012). $\alpha$-Spinasterol, also known as bessisterol, hitodesterol or $\alpha$-spinasterin, is a phytosterol first isolated from the spinach leaves and alfalfa (Nilius and Appendino 2013) that has been reported to possess antinociceptive, anti-inflammatory, antitumor, antiulcerogenic and cytoprotective properties (Jeon et al. 2005; Jeong et al. 2010; Trevisan et al. 2012; Klein-Junior et al. 2012; Borges et al. 2014). Notably, $\alpha$-spinasterol was reported to act as a selective TRPV1 antagonist with high penetration into the brain after systemic administration and it is devoid of side effects such as hyperthermia (Trevisan et al. 2012). These features make $\alpha$-spinasterol a useful tool for studying the role of the TRPV1 receptors in neurobiology of seizures.

Therefore, the present study was undertaken to evaluate the effect of $\alpha$-spinasterol on the seizure thresholds in three acute seizure tests in mice with predictive validity of clinical efficacy that are recommended for the primary screen of antiepileptic drugs (Löscher 2011). Moreover, acute adverse effects of $\alpha$-spinasterol on neuromuscular strength (the grip-strength test), motor coordination (the chimney test) and body temperature were investigated.

\section{Materials and methods}

\section{Animals}

All experiments were performed on naïve male Albino Swiss mice weighing 25-30 g. The animals were purchased from a licensed breeder (Laboratory Animals Breeding, Ilkowice, Poland) and housed in groups of 8-10 in Makrolon cages $(37 \mathrm{~cm} \times 21 \mathrm{~cm} \times 14 \mathrm{~cm})$ under strictly controlled laboratory conditions (temperature maintained at $22-23{ }^{\circ} \mathrm{C}$, relative humidity about $45-55 \%$ ) with an artificial 12/12 h light/dark cycle (light on at 6:00 a.m.). A nutritionally balanced rodent chow diet (Agropol S.J., Motycz, Poland) and tap water were continuously available. Before being used in the experiments, mice were allowed an adaptation period of at least 7 days. All experiments were performed between 8:00 am to 2:00 p.m. to minimize circadian influences, after a minimum 30-min acclimatization to the experimental room.

The total number of animals used in the present study was 227 . The animals were randomly assigned to the experimental groups as follows: 13-15 animals/group in the intravenous PTZ test, 18-21 animals/group in the MEST and $6 \mathrm{~Hz}$ seizure threshold test and 11-12 animals/group in the grip-strength test, the chimney test and for temperature measurement. The 'up-and-down' method for seizure 
threshold determination in the MEST and $6 \mathrm{~Hz}$ seizure tests requires $\sim 20$ animals per group because only one part of the group (with or without seizures) is used to calculate the seizure threshold. Since the grip-strength test, the chimney test and the temperature measurement are very quick and non-invasive procedures, all the tests performed in the same groups of animals shortly before the i.v. PTZ seizure test. This allowed to limit the total number of animals used in the present study, what was in accordance with the guidelines of the Ethical Committee.

The study was carried out under experimental protocols approved by the Ethical Committee of the Medical University in Lublin (license number 26/2014). All procedures were in strict compliance with the European Union Directive of 22 September 2010 (2010/63/EU) and Polish legislation concerning animal experimentation. All efforts were made to minimize animal suffering as well as the number of animals used in the study.

\section{Drugs}

$\alpha$-Spinasterol (5 $\alpha$-Stigmasta-7,22-dien-3 $\beta$-ol) was purchased from TRC (Toronto Research Chemicals Inc., Canada), dissolved in a $1 \%$ solution of dimethyl sulfoxide (DMSO, ICN Biomedicals, Inc., Aurora, OH, USA) in normal saline and administrated intraperitoneally (i.p.) in a constant volume of $10 \mathrm{ml} / \mathrm{kg}$. Pretreatment time for $\alpha$-spinasterol (30 min) was based on literature search (Klein-Junior et al. 2012; Borges et al. 2014). Control animals received i.p. injection of $1 \%$ DMSO.

The dose of $0.1 \mathrm{mg} / \mathrm{kg}$ (in a volume of $10 \mathrm{ml}$ per $\mathrm{kg}$ of body weight) was selected as an initial dose for all experiments. The dose was then increased or decreased depending on the observed results to see if there is a dosedependent effect.

Pentylenetetrazole (PTZ; Sigma-Aldrich, Poznań, Poland) was dissolved in normal saline and infused intravenously (i.v.).

\section{PTZ-induced seizure threshold test}

Thirty minutes following i.p. administration of $\alpha$-spinasterol or vehicle, mice were placed in the cylindrical plastic restrainer (12-cm long, 3-cm inner diameter). The lateral tail vein was catheterized with a 2-cm-long 27-gauge needle attached by polyethylene tubing PE20RW (Plastics One Inc., Roanoke, VA, USA) to a 5-ml plastic syringe containing a $1 \%$ solution of PTZ. The syringe was mounted on a syringe pump (model Physio 22, Hugo Sachs Elektronik-Harvard Apparatus GmbH, March-Hugstetten, Germany). After correct needle placement into the tail vein, which was verified by the appearance of blood in the tubing, mice were placed in a Plexiglas arena for behavioral observation. PTZ solution was infused at a constant rate of $0.2 \mathrm{ml} / \mathrm{min}$. The time intervals from the start of PTZ infusion to the onset of the following endpoints were recorded: (1) the initial myoclonic twitch, (2) generalized clonus with loss of righting reflex and (3) tonic forelimb extension. The seizure thresholds were calculated separately for each endpoint according to the following formula: threshold dose of PTZ $(\mathrm{mg} / \mathrm{kg})=$ (infusion duration $(\mathrm{s}) \times$ infusion rate $(\mathrm{ml} / \mathrm{s}) \times \mathrm{PTZ}$ concentration $(\mathrm{mg} /$ $\mathrm{ml}) \times 1000) /$ body weight $\mathrm{kg}$. Seizure thresholds were expressed as the amount of PTZ (in mg per $\mathrm{kg}$ ) \pm SEM (standard error of the mean) needed to produce the first apparent sign of each endpoint in each experimental group. Tonic convulsions were usually lethal for mice. All surviving animals were euthanized immediately after the end of the infusion.

\section{Maximal electroshock seizure threshold (MEST) test}

To determine the threshold for maximal electroshock seizures, constant current stimuli (50 Hz sine-wave, $0.2 \mathrm{~s}$ ) were applied via saline-soaked transcorneal electrodes after application of ocular anesthetic with the usage of rodent shocker (type 221; Hugo Sachs Elektronik, Freiburg, Germany). A drop of ocular anesthetic (1\% solution of tetracaine hydrochloride, Sigma-Aldrich) was applied into each eye $1 \mathrm{~min}$ before stimulation. During stimulation mice were restrained manually and immediately following stimulation were placed in a Plexiglas arena $(37 \mathrm{~cm} \times$ $21 \mathrm{~cm} \times 14 \mathrm{~cm}$ ) for behavioral observation for the presence or absence of seizure activity. Tonic hindlimb extension was taken as an endpoint. The current intensity was established according to an 'up-and-down' method described by Kimball et al. (1957). Current intensity was lowered or raised by 0.06-log intervals depending on whether the previously stimulated animal did or did not exert tonic hindlimb extension, respectively. The data obtained in groups of 19-20 animals were used to determine the threshold current causing endpoint in $50 \%$ of mice ( $\mathrm{CS}_{50}$ with confidence limits for $95 \%$ probability).

\section{Six-hertz (6 Hz) psychomotor seizure threshold test in mice}

Psychomotor seizures were induced via corneal stimulation. Square-wave alternating current stimuli (0.2-ms duration pulses at $6 \mathrm{~Hz}$ for $3 \mathrm{~s}$ ) were applied via salinesoaked corneal electrodes using a Grass S48 stimulator coupled with a constant current unit CCU1 (both from Grass Technologies, West Warwick, RI, USA). A drop of ocular anesthetic (1\% solution of tetracaine hydrochloride) was placed on the corneas before the stimulation and the electrodes were soaked in the $0.9 \%$ saline immediately 
before testing to ensure a good electrical contact. Mice were restrained manually during electrical stimulation and immediately following stimulation, the animals were placed in a Plexiglas arena $(37 \mathrm{~cm} \times 21 \mathrm{~cm} \times 14 \mathrm{~cm})$ for behavioral observation. Psychomotor seizures were characterized by immobility or stun posture, jaw and forelimb clonus, twitching of the vibrissae and elevated or Straub tail (Barton et al. 2001). The lack of the features listed above or the resumption of normal exploratory behavior within $10 \mathrm{~s}$ after stimulation were considered indicators of the absence of seizures. The mice were subjected to stimuli with different current intensities according to an 'up-anddown' method (Kimball et al. 1957). Each animal was stimulated only once at any given current intensity that was lowered or raised by 0.06-log intervals depending on whether the previously stimulated animal did or did not respond with convulsions, respectively. The data obtained in groups of 18-21 animals were used to determine the threshold current causing $6 \mathrm{~Hz}$-induced seizures in $50 \%$ of mice $\left(\mathrm{CS}_{50}\right.$ with confidence limits for $95 \%$ probability).

\section{Grip-strength test}

The acute adverse effect of $\alpha$-spinasterol on skeletal muscular strength in mice (12 animals/group) was determined in the grip-strength test. The grip-strength apparatus (BioSeb, Chaville, France) consisted of a steel wire grid $(8 \times 8 \mathrm{~cm})$ connected to an isometric force transducer. The mouse was lifted by its tail so that it could grasp the grid with its forepaws. The animal was then pulled back steadily by the tail until it released the grid. When the animal released the grid, the maximal grip-strength value (in newtons, N) of the animal was displayed on the screen. The procedure was repeated three times and the mean force exerted by each mouse before losing grip was recorded. Since body weight is a factor that affects the grip force, the mean force was normalized to body weight and expressed in $\mathrm{mN} / \mathrm{g} \pm \mathrm{SEM}$.

\section{Chimney test}

The chimney test was used to assess the acute adverse effects of $\alpha$-spinasterol on motor performance in mice (12 animals/group). In this test, the inability of an animal to climb backward up through a Plexiglas tube (inner diameter $3 \mathrm{~cm}$, length $30 \mathrm{~cm}$ ) within $60 \mathrm{~s}$ was an indication of motor impairment.

\section{Rectal temperature measurement}

Variation in rectal temperature was recorded using an electronic thermometer (ThermoWorks, Alpine, Utah, USA) by inserting the rectal probe to a depth of $\sim 2 \mathrm{~cm}$ into the rectum of the mouse. The rectal temperature of each animal was recorded just before administration of $\alpha$ spinasterol and 30 min later. The difference between the pre-injection and post-injection values was then calculated and expressed as $\Delta \mathrm{T}\left({ }^{\circ} \mathrm{C}\right)$.

\section{Statistical analysis}

Statistical analysis was performed using one-way analysis of variance (one-way ANOVA) followed by the Dunnett's post hoc test for multiple comparisons. To perform statistical analyses of data obtained in the MEST and the $6 \mathrm{~Hz}$ seizure tests, the $\mathrm{CS}_{50}$ values with $95 \%$ confidence limits were transformed into the mean value of logarithms (of current strength) with standard deviation. The results from the chimney test were analyzed with the Fisher's exact probability test. Statistical significance was noted when $\mathrm{p}$ values were equal to or less than 0.05. All calculations were carried out with GraphPad Prism version 5.03 for Windows (GraphPad Software, San Diego, CA, USA.).

\section{Results}

\section{Effects of $\alpha$-spinasterol in the PTZ-induced seizure threshold test}

The effect of $\alpha$-spinasterol on the threshold for the first myoclonic twitch is shown in Fig. 1a [one-way ANOVA: $F(4,63)=13.560, p<0.0001] . \alpha$-Spinasterol at a dose of $0.1 \mathrm{mg} / \mathrm{kg}$ slightly raised the threshold for the first myoclonic twitch ( $p<0.05$ vs. the vehicle-treated group). Higher doses, 0.5 and $1 \mathrm{mg} / \mathrm{kg}$, caused further increase in the seizure threshold ( $p<0.001$ vs. the control group). The lowest dose of $0.02 \mathrm{mg} / \mathrm{kg}$ was ineffective.

The effect of $\alpha$-spinasterol on the threshold for the generalized clonus with loss of righting reflex is shown in Fig. 1b [one-way ANOVA: $F(4,63)=3.412, p=0.014$ ] $\alpha$-Spinasterol at doses of 0.02 and $0.1 \mathrm{mg} / \mathrm{kg}$ had no effect on the seizure threshold. However, higher doses 0.5 and $1 \mathrm{mg} / \mathrm{kg}$ significantly raised the thresholds for the onset of clonic seizures as compared to the control group $(p<0.05)$.

Figure 1c presents the influence of $\alpha$-spinasterol on the threshold for the forelimb tonus (one-way ANOVA: $F(4,60)=1.991, p=0.107)$. $\alpha$-Spinasterol at any doses tested did not affect the susceptibility of mice to the PTZinduced forelimb tonus.

\section{Effects of $\alpha$-spinasterol in the MEST test}

The influence of $\alpha$-spinasterol on the threshold for the tonic hindlimb extension in the MEST test is shown in Fig. 2 


\section{A Myoclonic twitch}
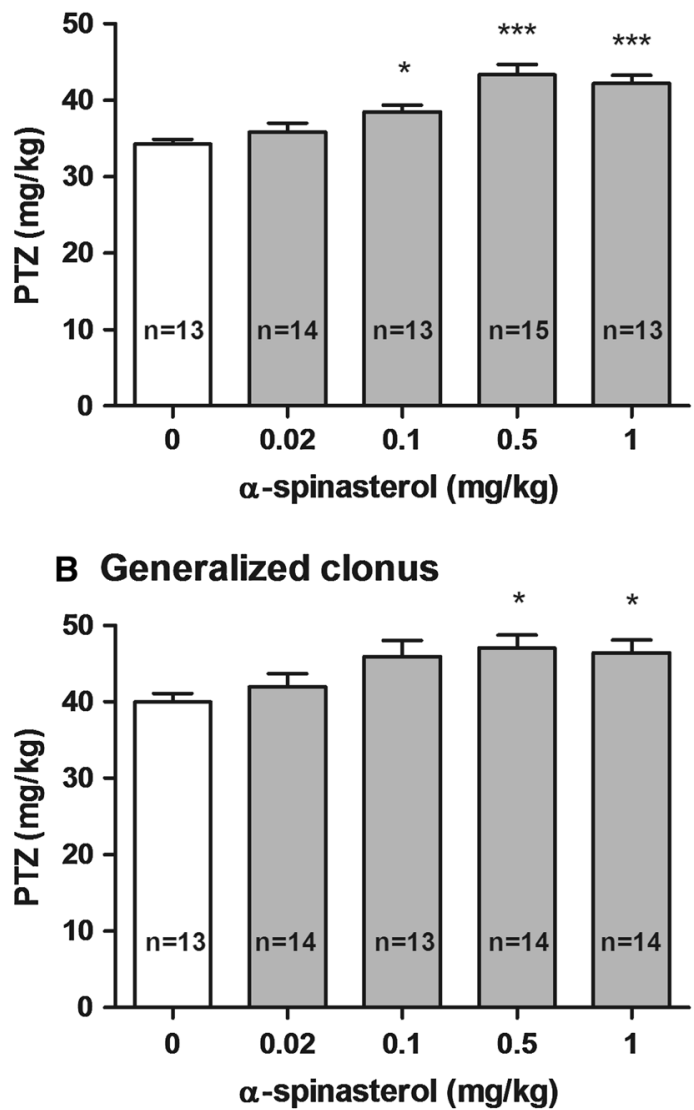

C Forelimb tonus

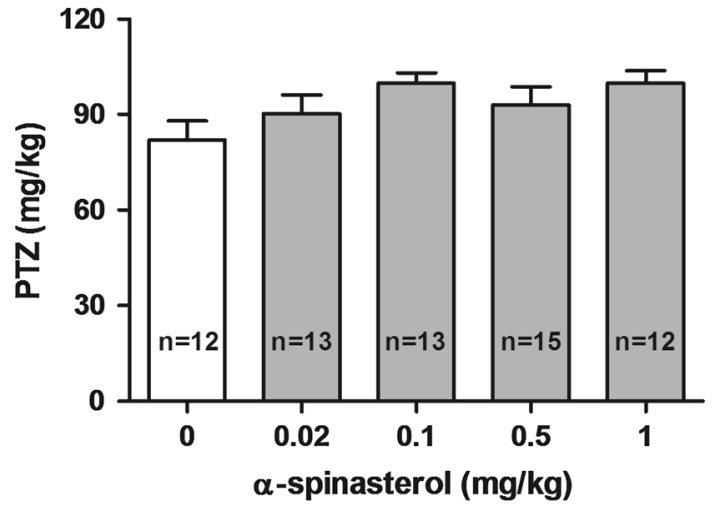

Fig. 1 Effect of $\alpha$-spinasterol on the threshold for the onset of first myoclonic twitch (a), generalized clonus (b) and forelimb tonus (c) in the i.v. PTZ seizure threshold test in mice. $\alpha$-Spinasterol was administered i.p. 30 min prior to the test. The doses are shown on the abscissa. Control animals received $1 \%$ DMSO. Each bar represents the mean $(\mathrm{mg} / \mathrm{kg}$ PTZ) + SEM. $* p<0.05 ; * * * p<0.001$ vs. the control group (one-way ANOVA followed by Dunnett's post hoc test)

[one-way ANOVA: $F(3,34)=5.752, \quad p=0.0027]$. $\alpha$-Spinasterol at a dose of $0.1 \mathrm{mg} / \mathrm{kg}$ did not affect the seizure threshold. Post hoc analysis revealed statistically

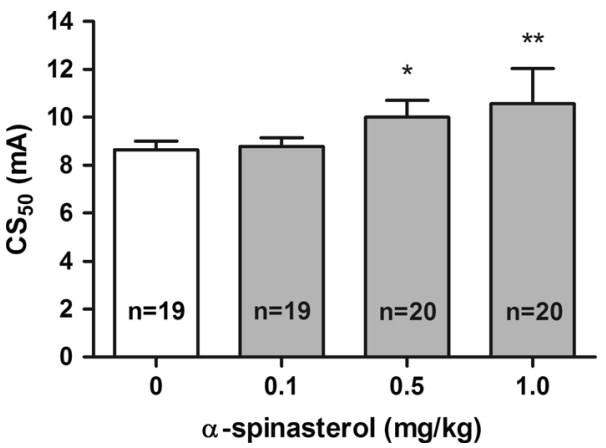

Fig. 2 Effect of $\alpha$-spinasterol on the seizure threshold in the MEST test. $\alpha$-Spinasterol was administered i.p. $30 \mathrm{~min}$ prior to the test. The doses are shown on the abscissa. Control animals received $1 \%$ DMSO. Data are presented as $\mathrm{CS}_{50}$ (in $\mathrm{mA}$ ) values with upper $95 \%$ confidence limits. Each $\mathrm{CS}_{50}$ value represents current intensity predicted to produce convulsions in $50 \%$ of mice. $* p<0.05$; $* * p<0.01$ vs. the control group (one-way ANOVA followed by Dunnett's post hoc test)

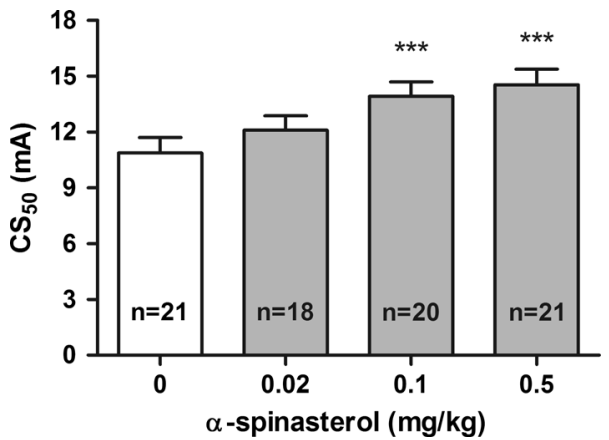

Fig. 3 Effect of $\alpha$-spinasterol on the seizure threshold in the $6 \mathrm{~Hz}$ seizure test. $\alpha$-Spinasterol was administered i.p. $30 \mathrm{~min}$ prior to the test. The doses are shown on the abscissa. Control animals received $1 \%$ DMSO. Data are presented as $\mathrm{CS}_{50}$ (in $\mathrm{mA}$ ) values with upper $95 \%$ confidence limits. Each $\mathrm{CS}_{50}$ value represents current intensity predicted to produce convulsions in $50 \%$ of mice. $* * * p<0.001 \mathrm{vs}$. the control group (one-way ANOVA followed by Dunnett's post hoc test)

significant increase in the $\mathrm{CS}_{50}$ value for doses of 0.5 and $1 \mathrm{mg} / \mathrm{kg}(p<0.05$ and $p<0.01$ vs. the vehicle-treated group, respectively).

\section{Effects of $\alpha$-spinasterol in the $6 \mathrm{~Hz}$ seizure test}

The effect of $\alpha$-spinasterol on the threshold for the $6 \mathrm{~Hz}$ induced psychomotor seizures is shown in Fig. 3 [one-way ANOVA: $F(3,33)=19.000, p<0.0001]$. The threshold for the $6 \mathrm{~Hz}$-induced seizures was not affected by $\alpha$-spinasterol injected at a dose of $0.02 \mathrm{mg} / \mathrm{kg}$. At higher doses $(0.1$ and $0.5 \mathrm{mg} / \mathrm{kg}), \alpha$-spinasterol significantly increased the $\mathrm{CS}_{50}$ values as compared to the control group $(p<0.001)$. 


\section{Effect of $\alpha$-spinasterol on the neuromuscular} strength, motor coordination and body temperature

Table 1 presents the influence of $\alpha$-spinasterol at doses ranging from 0.02 to $1 \mathrm{mg} / \mathrm{kg}$ on the neuromuscular strength, motor coordination and rectal temperature changes. $\alpha$-Spinasterol at any doses tested did not affect significantly the neuromuscular strength in mice, as determined in the grip-strength test [one-way ANOVA: $F(4,55)=0.890, p=0.476]$. Likewise, there was no significant impairment of motor coordination in the chimney test (Fisher's exact test: $p>0.05$ ). Furthermore, $\alpha$ spinasterol did not change significantly body temperature, as determined by comparison of the differences between the pre-injection and post-injection values of rectal temperature in mice [one-way ANOVA: $F(4,64)=1.910$, $p=0.120]$.

\section{Discussion}

Although the TRPV1 receptors are widely distributed thought the brain, still little is known about their function in the central nervous system (Martins et al. 2014). Recently, the TRPV1 receptors have been proposed to participate in pathogenesis of epilepsy (Fu et al. 2009; Gonzalez-Reyes et al. 2013; Shirazi et al. 2014). In the present study, we aimed to provide more data on the role of TRPV1 antagonism in the seizure threshold control.

Our findings showed that $\alpha$-spinasterol, a plant-derived compound that was reported to act as a TRPV1 antagonist, elevates the seizure threshold in three acute seizure threshold tests in mice. In the i.v. PTZ seizure threshold test, $\alpha$-spinasterol increased the seizure threshold for the onset of both the first myoclonic twitch and the generalized clonic seizures but had no significant effect on the PTZinduced tonic forelimb extension. In contrast, $\alpha$-spinasterol significantly raised the seizure threshold for the tonic hindlimb extension in the MEST test. The discrepancy between the effect of $\alpha$-spinasterol on tonic seizures in the i.v. PTZ test and the MEST test could have been a consequence of distinct mechanisms underlying seizure induction in these two tests. The i.v. PTZ seizure test employed in the present study models myoclonic and generalized tonic-clonic seizures (White 1998). Since PTZ is a blocker of the picrotoxin site of the chloride ionophore of the $\mathrm{GABA}_{\mathrm{A}}$ receptor complex, the PTZ seizure threshold is particularly sensitive to drugs that affect GABAergic neurotransmission (Löscher 2009). The MEST test is considered to be a model of generalized tonic-clonic (grand mal) seizures in humans and it can be useful for detecting anticonvulsant agents that act as sodium channel blockers (Castel-Branco et al. 2009; Nieoczym et al. 2014). In addition, our results demonstrated that $\alpha$-spinasterol significantly increased the threshold in the $6 \mathrm{~Hz}$ psychomotor seizure threshold test that is considered to be a model of therapy-resistant limbic seizures (Barton et al. 2001).

The anticonvulsant effect of $\alpha$-spinasterol might be a consequence of the inhibition of glutamate release. Glutamate is a major excitatory neurotransmitter that is responsible for the initiation and spread of seizure activity. Activation of the TRPV1 receptors leads to the increased $\mathrm{Na}^{+}$and $\mathrm{Ca}^{2+}$ ions influx and depolarization of neurons (Manna and Umathe 2012b). It was reported that stimulation of TRPV1 receptors increases the release of glutamate which in turn may affect the release of other neurotransmitters such as dopamine and GABA (Martins et al. 2014). Thus, the TRPV1 receptors appear to play a role in the regulation of neuronal excitability. For example, Mori et al. (2012) demonstrated that the TRPV1 receptors regulate cortical excitability in humans through modulation of glutamate release. Activation of the TRPV1 receptors with capsaicin or anandamide was also shown to induce neuronal death both in vitro and in vivo, which suggests a possible neuroprotective action of the TRPV1 receptor antagonists. Furthermore, the TRPV1 receptors were reported to play a role in hippocampal synaptic plasticity by

Table 1 Effect of $\alpha$-spinasterol on neuromuscular strength, motor coordination and rectal temperature in mice

\begin{tabular}{llllrr}
\hline Treatment & $\begin{array}{l}\text { Neuromuscular strength } \\
(\mathrm{mN} / \mathrm{g})\end{array}$ & $n$ & $\begin{array}{l}\text { Impairment of motor } \\
\text { coordination }(\%)\end{array}$ & $n$ & $\Delta T\left({ }^{\circ} \mathrm{C}\right)$ \\
\hline \% DMSO & $32.45 \pm 1.55$ & 12 & 0 & 12 & $+0.45 \pm 0.15$ \\
$\alpha$-Spinasterol $0.02 \mathrm{mg} / \mathrm{kg}$ & $29.73 \pm 1.43$ & 12 & 0 & 12 & $+0.22 \pm 0.15$ \\
$\alpha$-Spinasterol $0.1 \mathrm{mg} / \mathrm{kg}$ & $30.03 \pm 1.33$ & 12 & 8.33 & 12 & $+0.09 \pm 0.17$ \\
$\alpha$-Spinasterol $0.5 \mathrm{mg} / \mathrm{kg}$ & $28.88 \pm 1.49$ & 12 & 0 & 12 & $+0.24 \pm 0.15$ \\
$\alpha$-Spinasterol $1 \mathrm{mg} / \mathrm{kg}$ & $30.58 \pm 1.26$ & 12 & 0 & 12 & $+0.69 \pm 0.22$ \\
\hline
\end{tabular}

Data are presented as mean \pm SEM grip strengths in millinewtons per gram of mouse body weight (mN/g) from the grip-strength test, assessing skeletal muscular strength in mice, as a percentage of animals showing motor coordination impairment in the chimney test and as the differences between the pre-injection and post-injection values of rectal temperature in mice $(\Delta T)$ 
facilitating long-term potentiation and suppressing longterm depression. These effects may be important for seizure activity (Martins et al. 2014; Vilela et al. 2014). Hippocampus is a possible site of the anticonvulsant action of $\alpha$-spinasterol since it had cytoprotective effects against glutamate-induced neurotoxicity in mouse hippocampal HT22 cell (Jeong et al. 2010). However, this issue needs further investigation.

It is widely accepted that the immune system is involved in epileptogenesis ( $\mathrm{Li}$ et al. 2011). For that reason, antiinflammatory properties of $\alpha$-spinasterol might have contributed to its anticonvulsant effects. $\alpha$-Spinasterol suppressed production of pro-inflammatory cytokines and inflammatory mediators in the lipopolysaccharide-induced inflammation in mice (Borges et al. 2014) as well as in the BV2 microglia cells (Jeong et al. 2010). Noteworthy, $\alpha$ spinasterol was also reported to reduce the expression of the inducible nitric oxide (NO) synthase, thereby decreasing NO production. It should be mentioned here that NO oxide is a multifunctional signaling molecule but it is also a key mediator of excitotoxic neuronal injury and it is involved in neurobiology of numerous diseases including epilepsy (Rundfeldt et al. 1995; Nieoczym et al. 2012).

$\alpha$-Spinasterol has been chosen for our studies because of its aforementioned ability to cross the blood-brain barrier and low toxicity (Trevisan et al. 2012). It exerted anticonvulsant effects in mice at small doses of $0.02-1 \mathrm{mg} / \mathrm{kg}$ (i.p. route of administration), whereas the lethal dose $\left(\mathrm{LD}_{50}\right)$ of $\alpha$-spinasterol after i.p. injection in mice was estimated at $479 \mathrm{mg} / \mathrm{kg}$ (Zhou et al. 1985). In our study, $\alpha$ spinasterol produced no acute adverse effects. It did not affect motor coordination or neuromuscular strength, as assessed in the chimney and the grip-strength test, respectively. Moreover, no signs of hyperthermia at any dose used were observed, which is in line with the study of Trevisan et al. (2012). Altogether, $\boldsymbol{\alpha}$-spinasterol seems to be a useful tool for studying the role of central TRPV1 receptors in animal studies and perhaps in human subjects on condition that the ability to block the TRPV1 receptors is the main mode of action of $\alpha$-spinasterol.

It is widely known that the pharmacological blockade of the TRPV1 receptors elicits marked hyperthermia. The lack of hyperthermic response after $\alpha$-spinasterol administration may suggest that the compound acts in other manners that exert antipyretic effects. However, several hyperthermiafree TRPV1 antagonists have been already developed (Lehto et al. 2008; Garami et al. 2010; Watabiki et al. 2011; Andreev et al. 2013; Voight et al. 2014). Furthermore, Garami et al. (2010) reported that the hypothermia induced by TRPV1 antagonists is triggered by the blockade of the proton mode of TRPV1 activation. They concluded that the hyperthermia-free TRPV1 antagonists do not block TRPV1 activation by protons and they work in different manner. Further studies on the pharmacological profile of $\alpha$-spinasterol are required to elucidate its mode of action at the TRPV1 receptors.

It is also worth mentioning that $\alpha$-spinasterol is a plant steroid. Natural remedies have drawn attention of researchers as a promising source of new biologically active compounds for years. A number of herbs used in folk medicine as well as single plant-derived compounds have been shown to possess anticonvulsant activity (Schachter 2009). Cannabinoids can be an example here (Devinsky et al. 2014). Interestingly, the TRPV1 receptors are often co-localized with cannabinoid $\mathrm{CB}_{1}$ receptors. Anandamide, an endogenous agonist of $\mathrm{CB}_{1}$ receptors, was shown to activate the TRPV1 receptors, therefore it exhibits both pro- (at lower doses) and anticonvulsant (at higher doses) effects by activating the TRPV1 and $\mathrm{CB}_{1}$ receptors, respectively (Manna and Umathe 2012b). We can speculate that the endocannabinoid system may be also somehow involved in the anticonvulsant effect of $\alpha$-spinasterol but this suggestion should be carefully evaluated in other studies.

In conclusion, the present study demonstrates for the first time that $\alpha$-spinasterol, a TRPV1 receptor antagonist, exerts acute anticonvulsant effects in three distinct seizure threshold tests in mice. Our findings add support to the thesis concerning suppression of ongoing seizures by TRPV1 antagonists. $\alpha$-Spinasterol may represent a new pharmacological approach towards the development of novel or adjuvant therapy for seizure disorders. Nevertheless, further detailed studies on the anticonvulsant action of $\alpha$-spinasterol in other animal models of seizures and epilepsy are required. Its possible interactions with antiepileptic drugs should be also evaluated.

Acknowledgments This study was supported by Funds for Statutory Activity of Maria Curie-Skłodowska University, Lublin, Poland.

\section{Conflict of interest None.}

Open Access This article is distributed under the terms of the Creative Commons Attribution License which permits any use, distribution, and reproduction in any medium, provided the original author(s) and the source are credited.

\section{References}

Andreev YA, Kozlov SA, Korolkova YV, Dyachenko IA, Bondarenko DA, Skobtsov DI, Murashev AN, Kotova PD, Rogachevskaja OA, Kabanova NV, Kolesnikov SS, Grishin EV (2013) Polypeptide modulators of TRPV1 produce analgesia without hyperthermia. Mar Drugs 11:5100-5115

Barton ME, Klein BD, Wolf HH, White HS (2001) Pharmacological characterization of the $6 \mathrm{~Hz}$ psychomotor seizure model of partial epilepsy. Epilepsy Res 47:217-227

Bhaskaran MD, Smith BN (2010) Effects of TRPV1 activation on synaptic excitation in the dentate gyrus of a mouse model of temporal lobe epilepsy. Exp Neurol 223:529-536 
Borges FR, Silva MD, Cordova MM, Schambach TR, Pizzolatti MG, Santos AR (2014) Anti-inflammatory action of hydroalcoholic extract, dichloromethane fraction and steroid alpha-spinasterol from Polygala sabulosa in LPS-induced peritonitis in mice. J Ethnopharmacol 151:144-150

Castel-Branco MM, Alves GL, Figueiredo IV, Falcao AC, Caramona MM (2009) The maximal electroshock seizure (MES) model in the preclinical assessment of potential new antiepileptic drugs. Methods Find Exp Clin Pharmacol 31:101-106

Caterina MJ, Schumacher MA, Tominaga M, Rosen TA, Levine JD, Julius D (1997) The capsaicin receptor: a heat-activated ion channel in the pain pathway. Nature 389:816-824

Devinsky O, Cilio MR, Cross H, Fernandez-Ruiz J, French J, Hill C, Katz R, Di MV, Jutras-Aswad D, Notcutt WG, Martinez-Org Robson PJ, Rohrback BG, Thiele E, Whalley B, Friedman D (2014) Cannabidiol: pharmacology and potential therapeutic role in epilepsy and other neuropsychiatric disorders. Epilepsia 55:791-802

Fu M, Xie Z, Zuo H (2009) TRPV1: a potential target for antiepileptogenesis. Med Hypotheses 73:100-102

Garami A, Shimansky YP, Pakai E, Oliveira DL, Gavva NR, Romanovsky AA (2010) Contributions of different modes of TRPV1 activation to TRPV1 antagonist-induced hyperthermia. J Neurosci 30:1435-1440

Gonzalez-Reyes LE, Ladas TP, Chiang CC, Durand DM (2013) TRPV1 antagonist capsazepine suppresses 4-AP-induced epileptiform activity in vitro and electrographic seizures in vivo. Exp Neurol 250:321-332

Jeon GC, Park MS, Yoon DY, Shin CH, Sin HS, Um SJ (2005) Antitumor activity of spinasterol isolated from Pueraria roots. Exp Mol Med 37:111-120

Jeong GS, Li B, Lee DS, Kim KH, Lee IK, Lee KR, Kim YC (2010) Cytoprotective and anti-inflammatory effects of spinasterol via the induction of heme oxygenase-1 in murine hippocampal and microglial cell lines. Int Immunopharmacol 10:1587-1594

Kauer JA, Gibson HE (2009) Hot flash: TRPV channels in the brain. Trends Neurosci 32:215-224

Kimball AW, Burnett WT Jr, Doherty DG (1957) Chemical protection against ionizing radiation. I. Sampling methods for screening compounds in radiation protection studies with mice. Radiat Res 7:1-12

Klein-Junior LC, Meira NA, Bresolin TM, Cechinel-Filho V, Quintao NL (2012) Antihyperalgesic activity of the methanol extract and some constituents obtained from Polygala cyparissias (Polygalaceae). Basic Clin Pharmacol Toxicol 111:145-153

Lehto SG, Tamir R, Deng H, Klionsky L, Kuang R, Le A, Lee D, Louis JC, Magal E, Manning BH, Rubino J, Surapaneni S, Tamayo N, Wang T, Wang J, Wang J, Wang W, Youngblood B, Zhang M, Zhu D, Norman MH, Gavva NR (2008) Antihyperalgesic effects of (R, E)-N-(2-hydroxy-2,3-dihydro-1H-inden-4yl)-3-(2-(piperidin-1-yl)-4-(trifluorom ethyl)phenyl)-acrylamide (AMG8562), a novel transient receptor potential vanilloid type 1 modulator that does not cause hyperthermia in rats. J Pharmacol Exp Ther 326:218-229

Li G, Bauer S, Nowak M, Norwood B, Tackenberg B, Rosenow F, Knake S, Oertel WH, Hamer HM (2011) Cytokines and epilepsy. Seizure 20:249-256

Löscher W (2009) Preclinical assessment of proconvulsant drug activity and its relevance for predicting adverse events in humans. Eur J Pharmacol 610:1-11

Löscher W (2011) Critical review of current animal models of seizures and epilepsy used in the discovery and development of new antiepileptic drugs. Seizure 20:359-368

Manna SS, Umathe SN (2012a) A possible participation of transient receptor potential vanilloid type 1 channels in the antidepressant effect of fluoxetine. Eur J Pharmacol 685:81-90
Manna SS, Umathe SN (2012b) Involvement of transient receptor potential vanilloid type 1 channels in the pro-convulsant effect of anandamide in pentylenetetrazole-induced seizures. Epilepsy Res 100:113-124

Martins D, Tavares I, Morgado C (2014) "Hotheaded": the role OF TRPV1 in brain functions. Neuropharmacology 85:151-157

Mori F, Ribolsi M, Kusayanagi H, Monteleone F, Mantovani V, Buttari F, Marasco E, Bernardi G, Maccarrone M, Centonze D (2012) TRPV1 channels regulate cortical excitability in humans. J Neurosci 32:873-879

Nieoczym D, Socała K, Łuszczki JJ, Czuczwar SJ, Wlaź P (2012) Influence of sildenafil on the anticonvulsant action of selected antiepileptic drugs against pentylenetetrazole-induced clonic seizures in mice. J Neural Transm 119:923-931

Nieoczym D, Socała K, Raszewski G, Wlaź P (2014) Effect of quercetin and rutin in some acute seizure models in mice. Prog Neuropsychopharmacol Biol Psychiatry 54:50-58

Nilius B, Appendino G (2013) Spices: the savory and beneficial science of pungency. Rev Physiol Biochem Pharmacol 164:1-76

Pingle SC, Matta JA, Ahern GP (2007) Capsaicin receptor: TRPV1 a promiscuous TRP channel. Handb Exp Pharmacol:155-171

Premkumar LS, Sikand P (2008) TRPV1: a target for next generation analgesics. Curr Neuropharmacol 6:151-163

Rundfeldt C, Koch R, Richter A, Mevissen M, Gerecke U, Löscher W (1995) Dose-dependent anticonvulsant and proconvulsant effects of nitric oxide synthase inhibitors on seizure threshold in a cortical stimulation model in rats. Eur J Pharmacol 274:73-81

Schachter SC (2009) Botanicals and herbs: a traditional approach to treating epilepsy. Neurotherapeutics 6:415-420

Shirazi M, Izadi M, Amin M, Rezvani ME, Roohbakhsh A, Shamsizadeh A (2014) Involvement of central TRPV1 receptors in pentylenetetrazole and amygdala-induced kindling in male rats. Neurol Sci 35:1235-1241

Sun FJ, Guo W, Zheng DH, Zhang CQ, Li S, Liu SY, Yin Q, Yang H, Shu HF (2013) Increased expression of TRPV1 in the cortex and hippocampus from patients with mesial temporal lobe epilepsy. J Mol Neurosci 49:182-193

Szallasi A, Cortright DN, Blum CA, Eid SR (2007) The vanilloid receptor TRPV1: 10 years from channel cloning to antagonist proof-of-concept. Nat Rev Drug Discov 6:357-372

Trevisan G, Rossato MF, Walker CI, Klafke JZ, Rosa F, Oliveira SM, Tonello R, Guerra GP, Boligon AA, Zanon RB, Athayde ML, Ferreira J (2012) Identification of the plant steroid alphaspinasterol as a novel transient receptor potential vanilloid 1 antagonist with antinociceptive properties. J Pharmacol Exp Ther 343:258-269

Vilela LR, Medeiros DC, de Oliveira AC, Moraes MF, Moreira FA (2014) Anticonvulsant effects of $\mathrm{N}$-arachidonoyl-serotonin, a dual fatty acid amide hydrolase enzyme and transient receptor potential vanilloid type-1 (TRPV1) channel blocker, on experimental seizures: the roles of cannabinoid CB1 receptors and TRPV1 channels. Basic Clin Pharmacol Toxicol 115:330-334

Voight EA, Gomtsyan AR, Daanen JF, Perner RJ, Schmidt RG, Bayburt EK, DiDomenico S, McDonald HA, Puttfarcken PS, Chen J, Neelands TR, Bianchi BR, Han P, Reilly RM, Franklin PH, Segreti JA, Nelson RA, Su Z, King AJ, Polakowski JS, Baker SJ, Gauvin DM, Lewis LR, Mikusa JP, Joshi SK, Faltynek CR, Kym PR, Kort ME (2014) Discovery of (R)-1-(7-chloro-2,2bis(fluoromethyl)chroman-4-yl)-3-(3-methylisoquinolin-5yl)urea (A-1165442): a temperature-neutral transient receptor potential vanilloid-1 (TRPV1) antagonist with analgesic efficacy. J Med Chem 57:7412-7424

Vriens J, Appendino G, Nilius B (2009) Pharmacology of vanilloid transient receptor potential cation channels. Mol Pharmacol $75: 1262-1279$ 
Watabiki T, Kiso T, Kuramochi T, Yonezawa K, Tsuji N, Kohara A, Kakimoto S, Aoki T, Matsuoka N (2011) Amelioration of neuropathic pain by novel transient receptor potential vanilloid 1 antagonist AS1928370 in rats without hyperthermic effect. J Pharmacol Exp Ther 336:743-750
White HS (1998) Chemoconvulsants. In: Peterson SL, Albertson TE (eds) Neuropharmacology Methods in Epilepsy Research. CRC Press, Boca Raton FL, pp 27-40

Zhou CC, Sun XB, Liu JY, Luo SQ, Lu CY (1985) Anti-inflammatory effect of alpha-spinasterol. Yao Xue Xue Bao 20:257-261 